\title{
Kocuria kristinae septic arthritis associated with infectious endocarditis in a hemodialysis patient with diabetes mellitus: a case report and literature review
}

\author{
Taro Horino*, Yoshiko Shimamura, Koji Ogata, Kosuke Inoue and Yoshio Terada
}

\begin{abstract}
Background: Kocuria kristinae is an aerobic Gram-positive coccus that is considered ubiquitous and nonpathogenic in healthy individuals. Furthermore, only 27 reports have described cases of critical infections with this microorganism, which is notoriously difficult to identify.

Case presentation: We report the case of a 61-year-old male hemodialysis patient with diabetes mellitus, who developed severe septic arthritis that was associated with infectious endocarditis, which was identified using ${ }^{18}$ F-fluorodeoxyglucose positron-emission tomography/computed tomography (FDG-PET-CT). K. kristinae was identified in two separate blood cultures. The patient recovered immediately after being treated using piperacillin followed by ampicillin/sulbactam and gentamicin.

Conclusions: To the best of our knowledge, this is the first case of $K$. kristinae septic arthritis associated with infectious endocarditis in a hemodialysis patient with diabetes mellitus. We suggest that physicians consider the pathogenic potential of $K$. kristinae, which can cause fatal infections, such as septic arthritis and infectious endocarditis, in immunocompromised patients. FDG-PET-CT is a useful and safe diagnostic tool for determining the cause of inflammatory disease in dialysis patients.
\end{abstract}

Keywords: Kocuria kristinae, Septic arthritis, Infectious endocarditis, Hemodialysis, FDG-PET-CT

\section{Background}

In Japan, the number of patients with diabetes is increasing every year, as is the rate of renal replacement therapy (RRT) for treating diabetic nephropathy. Both end-stage renal disease (ESRD) and diabetes mellitus are severe immunocompromised states, and dialysis patients are prone to infectious complications. Furthermore, we believe that patients with diabetes mellitus are predisposed to invasive infections. Therefore, we describe the case of a hemodialysis patient who had a wound infection and bacteremia with Kocuria kristinae, which is a microorganism that is considered non-pathogenic in healthy individuals. In addition, we provide a review of case reports regarding $K$. kristinae infections in humans.

\footnotetext{
* Correspondence: horinott@yahoo.co.jp

Department of Endocrinology, Metabolism and Nephrology, Kochi Medical School, Kohasu, Okoh-cho, Nankoku 783-8505, Kochi, Japan
}

\section{Case presentation}

A 61-year-old male hemodialysis patient with a history of diabetes mellitus and polyarthralgia was referred to our hospital. Two months before the referral, the patient had arthralgia of the right knee, which exhibited swelling, tenderness, and restricted motion. The patient subsequently experienced severe polyarthralgia that involved both shoulders, wrists, hip joints, foot joints, and the left knee joint, as well as rapidly progressing severe lumbago. At the admission, his temperature was $36.6{ }^{\circ} \mathrm{C}$. A physical examination revealed swelling and warmth in all joints that the patient identified as being painful. The laboratory test results are shown in Table 1. A chest radiograph revealed mild cardiomegaly without other remarkable findings. Joint radiographs revealed no deformities. Magnetic resonance imaging (MRI) of the left hip joint revealed high-intensity lesions surrounding 
Table 1 Laboratory data at admission

\begin{tabular}{|c|c|c|c|c|c|c|c|}
\hline CBC (normal range) & & Blood chemistry & & Tumor markers & & Blood culture & \\
\hline RBC (400-552) & $239 \times 10^{4} / \mathrm{mm}^{3}$ & FBS (70-110) & 179 mg/dL & CEA $(<3.4)$ & $0.8 \mathrm{ng} / \mathrm{mL}$ & Kocuria kristinae & $(+)$ \\
\hline $\mathrm{Hb}(13.2-17.2)$ & $6.9 \mathrm{~g} / \mathrm{dL}$ & Alp (104-338) & $501 \mathrm{U} / \mathrm{L}$ & CA19-9 $(<37)$ & $2.8 \mathrm{U} / \mathrm{mL}$ & Antimicrobial susceptibilities (MIC) & $\mu \mathrm{g} / \mathrm{mL}$ \\
\hline $\mathrm{Ht}(40.4-51.1)$ & $21.9 \%$ & $\gamma$-GTP (5-70) & $41 \mathrm{U} / \mathrm{L}$ & Infection & & Penicillin & 0.12 \\
\hline Plt (14.8-33.9) & $46.8 \times 10^{4} / \mathrm{mm}^{3}$ & t-Bil $(0.2-1.2)$ & $0.3 \mathrm{mg} / \mathrm{dL}$ & $\mathrm{HBs} \mathrm{Ag}$ & $(-)$ & Oxacillin & $\leq 2.0$ \\
\hline WBC (3.6-9.6) & $5.6 \times 10^{3} / \mathrm{mm}^{3}$ & d-Bil (0-0.4) & $0.0 \mathrm{mg} / \mathrm{dL}$ & $\mathrm{HCV} A \mathrm{~b}$ & $(-)$ & Ampicillin & $\leq 0.25$ \\
\hline neu & $73.0 \%$ & ChE (168-470) & $123 \mathrm{U} / \mathrm{L}$ & HTLV-I Ab & $(-)$ & Cefazolin & $\leq 8.0$ \\
\hline lym & $8.0 \%$ & ALT (8-42) & $24 \mathrm{U} / \mathrm{L}$ & EBV & & Cefotaxime & $\leq 8.0$ \\
\hline mon & $13.0 \%$ & AST (13-33) & $37 \mathrm{U} / \mathrm{L}$ & VCA-lgG & $\times 640$ & cefepime & $\leq 8.0$ \\
\hline eos & $6.0 \%$ & LDH (119-229) & $125 \mathrm{U} / \mathrm{L}$ & VCA-lgM & $x<10$ & Cefotiam & $\leq 8.0$ \\
\hline bas & $0.0 \%$ & CPK (62-287) & $10 \mathrm{U} / \mathrm{L}$ & EBNA & $\times 20$ & Cefpirome & $\leq 8.0$ \\
\hline aty-ly & $0.0 \%$ & Crn $(0.6-1.1)$ & $10.3 \mathrm{mg} / \mathrm{dL}$ & Mumps & $(-)$ & Cefozopran & $\leq 8.0$ \\
\hline Electrolytes & & BUN (8-20) & $52 \mathrm{mg} / \mathrm{dL}$ & Herpes zoster & $(-)$ & Cefmetazole & $\leq 16.0$ \\
\hline $\mathrm{Na}(136-145)$ & $137 \mathrm{mmol} / \mathrm{L}$ & UA (3.4-7.8) & $8.5 \mathrm{mg} / \mathrm{dL}$ & Parvovirus B19 & $(-)$ & Cefdinir & $\leq 1.0$ \\
\hline K (3.4-4.5) & $4.4 \mathrm{mmol} / \mathrm{L}$ & Amy (37-125) & $71 \mathrm{U} / \mathrm{L}$ & Syphilis & $(-)$ & Cefditoren & $\leq 1.0$ \\
\hline $\mathrm{Cl}(100-108)$ & $99 \mathrm{mmol} / \mathrm{L}$ & TG (30-150) & $106 \mathrm{mg} / \mathrm{dL}$ & QFT & $(-)$ & Flomoxef & $\leq 8.0$ \\
\hline $\mathrm{Ca}(8.7-11.0)$ & $10.2 \mathrm{mg} / \mathrm{dL}$ & $\mathrm{H}-\mathrm{Chol}(>40)$ & $17 \mathrm{mg} / \mathrm{dL}$ & Candida Ab & $(-)$ & Imipenem/cilastatin & $\leq 4.0$ \\
\hline$P(2.5-4.5)$ & $4.7 \mathrm{mg} / \mathrm{dL}$ & L-Chol $(<140)$ & $61 \mathrm{mg} / \mathrm{dL}$ & $\beta$-D-glucan & $(-)$ & Meropenem & $\leq 4.0$ \\
\hline $\mathrm{Mg}(1.8-2.4)$ & $2.5 \mathrm{mg} / \mathrm{dL}$ & Serological examinations & & Chlamydia trachomatis & & Amoxicillin & $\leq 4.0$ \\
\hline Proteinogram & & $\operatorname{CRP}(<0.3)$ & $35.5 \mathrm{mg} / \mathrm{dL}$ & $\lg G$ & $(-)$ & Gentamicin & $\leq 4.0$ \\
\hline $\operatorname{TP}(6.7-8.1)$ & $7.1 \mathrm{~g} / \mathrm{dL}$ & SAA $(<8.0)$ & $1843.9 \mathrm{mg} / \mathrm{mL}$ & $\lg A$ & $(-)$ & Amikacin & $\leq 16.0$ \\
\hline Alb (3.9-4.9) & $2.6 \mathrm{~g} / \mathrm{dL}$ & MMP-3 (36.9-121.0) & $586.4 \mathrm{ng} / \mathrm{mL}$ & Chlamydia pneumoniae & & Arbekacin & $\leq 4.0$ \\
\hline Glb & $4.5 \mathrm{~g} / \mathrm{dL}$ & CH50 (30-45) & $47.0 \mathrm{U} / \mathrm{mL}$ & $\lg G$ & $(-)$ & Erythromycin & $\leq 0.5$ \\
\hline a1 & $11.2 \%$ & C3 (65-135) & $131.5 \mathrm{mg} / \mathrm{dL}$ & $\lg A$ & $(-)$ & Clarithromycin & $\leq 2.0$ \\
\hline$a 2$ & $16.6 \%$ & C4 (13-35) & $31.7 \mathrm{mg} / \mathrm{dL}$ & Synovial fluid & & Clindamycin & $\leq 0.5$ \\
\hline$\beta$ & $10.7 \%$ & ANA & $(-)$ & Glossly purulent material & & Minocycline & $\leq 4.0$ \\
\hline Y & $34.3 \%$ & ds-DNA Ab & $(-)$ & WBC & $13,200 \times 10^{3} / \mathrm{mm}^{3}$ & Linezolid & $\leq 2.0$ \\
\hline $\operatorname{lgG}(870-1700)$ & $2519 \mathrm{mg} / \mathrm{dL}$ & SSA Ab & $(-)$ & neu & $95.0 \%$ & Vancomycin & $\leq 2.0$ \\
\hline $\lg A(110-410)$ & $497 \mathrm{mg} / \mathrm{dL}$ & SSB Ab & $(-)$ & pla & $5.0 \%$ & Teicoplanin & $\leq 8.0$ \\
\hline $\operatorname{lgM}(35-220)$ & 87 mg/dL & RF & $(-)$ & Crystals & $(-)$ & Fosfomycin & $\leq 4.0$ \\
\hline
\end{tabular}


Table 1 Laboratory data at admission (Continued)

\begin{tabular}{|c|c|c|c|c|c|c|c|}
\hline M-protein & $(-)$ & ACPA & $(-)$ & Culture & $(-)$ & Levofloxacin & $\leq 1.0$ \\
\hline $\mathrm{HbA1c}(4.6-6.2)$ & $7.9 \%$ & MPO-ANCA & $(-)$ & & & Sulfamethoxazole/trimethoprim & $\leq 2.0$ \\
\hline ESR $(<20)$ & $>140 \mathrm{~mm} / \mathrm{h}$ & PR3-ANCA & $(-)$ & & & Rifampicin & $\leq 1.0$ \\
\hline
\end{tabular}

Abbreviations: $C B C$ complete blood cell count, $R B C$ red blood cell count, $H b$ hemoglobin, $H t$ hematocrit, Plt platelet, ESR erythrocyte sedimentation rate, WBC white blood cell count, neu neutrophils, lym lymphocytes, mon monocytes, eoseosinophils, bas basophils, aty-ly atypical lymphocytes, Na sodium, $K$ potassium, $C l$ chlorine, Ca calcium, $P$ phosphorus, Mg magnesium, TP total protein, Alb albumin, Glb globulin, IgG

immunoglobulin G, IgA immunoglobulin A, IgM immunoglobulin M, FBS fasting blood sugar, Alp alkaline phosphatase, $\gamma$-GTP $\gamma$-glutamyltransferase, $t$-Bil total bilirubin, $d$-Bil direct bilirubin, ChE cholinesterase, ALT

alanine transaminase, AST aspartate aminotransferase, $L D H$ lactate dehydrogenase, CPK creatine phosphokinase, Crn creatinine, BUN blood urea nitrogen, UA uric acid, Amy amylase, TG triglyceride, $H$-Chol high-density alanine transaminase, AST aspartate aminotransferase, LDH lactate dehydrognase, $C P K C r$, $A$,
lipoprotein cholesterol,

L-Chol low-density lipoprotein cholesterol, CRP C-reactive protein, SAA serum amyloid A, MMP-3 matrix metalloproteinase-3, CH50 complement activity, C3 complement 3, C4 complement 4, ANA antinuclear antibody, SSA Ab anti-SS-A/Ro antibody,SSB Ab anti-SS-B/La antibody, RF rheumatoid factor, ACPA anti-cyclic citrullinated peptide antibody, MPO-ANCA myeloperoxidase-anti-neutrophil cytoplasmic antibody, PR3-ANCA serine proteinase3-anti-neutrophil cytoplasmic antibody, HBS Ab hepatitis B surface antigen, HCV Ab hepatitis C virus antibody, HTLV-I Ab human T-lymphotropic virus type 1 antibody,pla plasma cell, EBV Epstein-Barr virus, VCA viral capsid antigen, EBNA Epstein-Barr nuclear antigen, QFT QuantiFERON-TB, pla plasma cell 

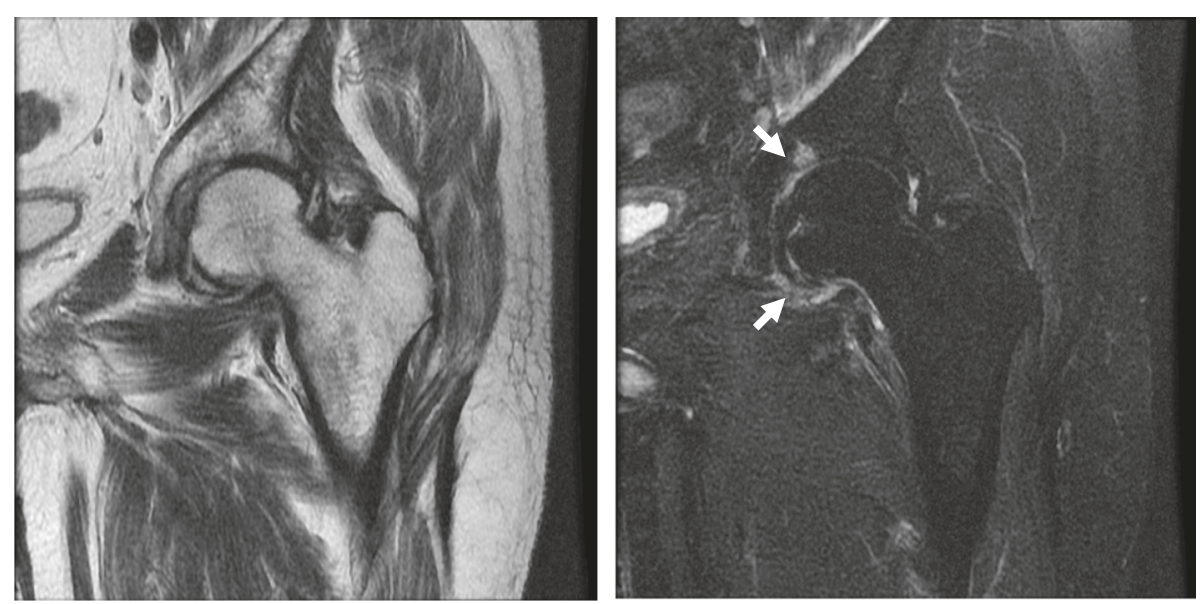

Fig. 1 The magnetic resonance imaging findings. The magnetic resonance findings from the left hip joint reveal high-intensity lesions (white arrows) surrounding the head of the femoral bone in the T2-weighted image (right panel)

the head of the femoral bone on the T2-weighted image (Fig. 1). ${ }^{18}$ F-fluorodeoxyglucose positron-emission tomography/computed tomography (FDG-PET-CT) revealed short segments of increased FDG uptake within the shoulders, wrists, hip joints, knees, and foot joints (Fig. 2). We had performed arthrocentesis at the admission, and an aspiration specimen from the right knee joint yielded grossly purulent material. Synovial fluid white cell counts were $13,200 / \mathrm{mm}^{3}$, with $95 \%$ polymorphonuclear leukocytes and $5 \%$ monomorphonuclear leukocytes. Although the synovial fluid culture was negative, clusters of Grampositive cocci were isolated from a blood specimen that was taken at the admission. Two blood cultures were both positive for $K$. kristinae, and these results were confirmed using the Vitek 2 system. The isolate was sensitive to all tested antibiotics (Table 1). We started treatment using intravenous piperacillin (2 g once per day), and the polyarthritis immediately improved. After 14 days of antibiotic treatment, the
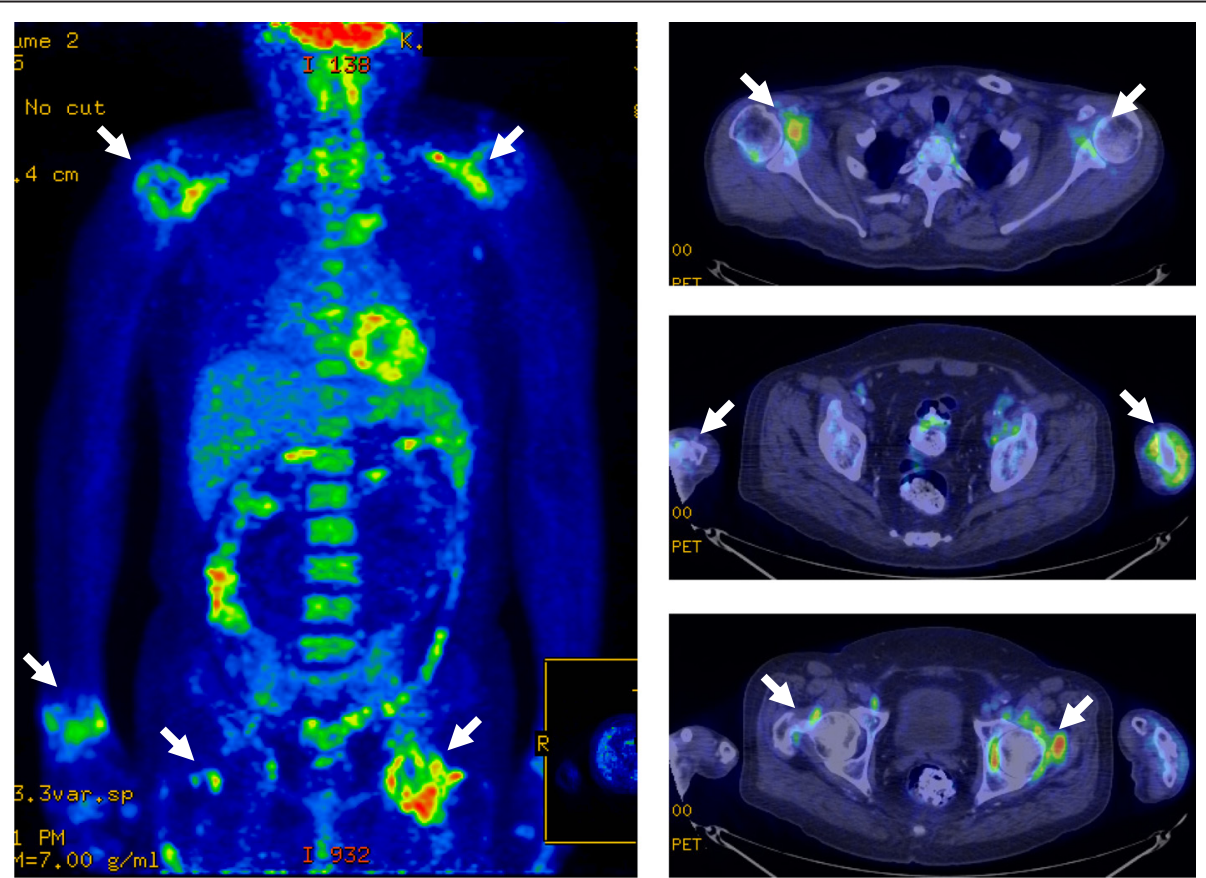

Fig. 2 The ${ }^{18} \mathrm{~F}$-fluorodeoxyglucose positron-emission tomography/computed tomography findings. ${ }^{18} \mathrm{~F}$-fluorodeoxyglucose positron-emission tomography/computed tomography reveals short segments of increased fluorodeoxyglucose uptake (white arrows) within the shoulders, wrists, hip joints, knees, and foot joints 

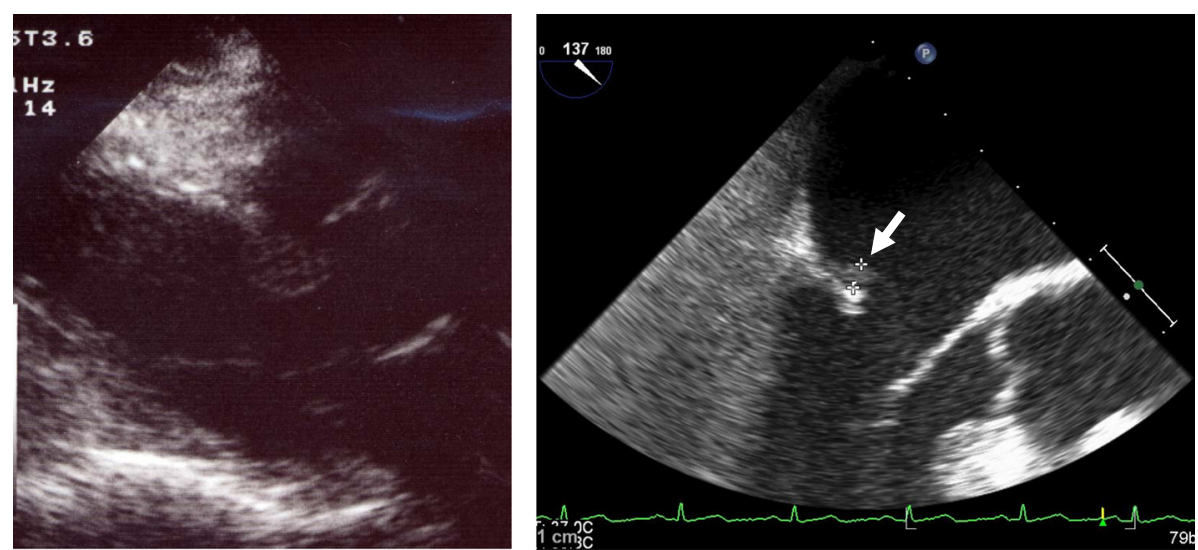

Fig. 3 The echocardiography findings. (Left panel) Echocardiography reveals no remarkable findings at 2 years before the presentation. (Right panel) Echocardiography at 1 month after the admission reveals mitral valve vegetation

patient's C-reactive protein levels were $0.8 \mathrm{mg} / \mathrm{dL}$ and the other laboratory data were normalized.

Electrocardiography detected no remarkable findings during his clinical course. However, 1 month after the admission, echocardiography detected vegetation on the mitral valve, which was compatible with infectious endocarditis (Fig. 3, right panel), although there had been no findings of vegetation at 2 years before the admission (Fig. 3, left panel). Physical examination after the echocardiography revealed Janeway's lesions, although we did not detect Osler's nodes or Roth's spots. Therefore, we stopped the intravenous piperacillin therapy and started treatment using intravenous ampicillin/sulbactam $(1.5 \mathrm{~g}$ every other day) and intravenous gentamicin $(100 \mathrm{mg}$ every other day). The patient's clinical course was uneventful, and he was later discharged to our outpatient clinic (Fig. 4).

\section{Discussion}

K. kristinae was first described as Micrococcus kristinae in 1974 and was subsequently classified as Micrococcus spp., which is now separated into Micrococcus, Nesterenkonia, Kytococcus, Dermacoccus, and Kocuria $[1,2]$. K. kristinae is a strictly aerobic species that is commonly identified among skin and oral flora [3]. Most physicians consider Micrococcus spp. (including Kocuria) nonpathogenic, and we initially assumed that the blood cultures from the present case were negative for pathogenic

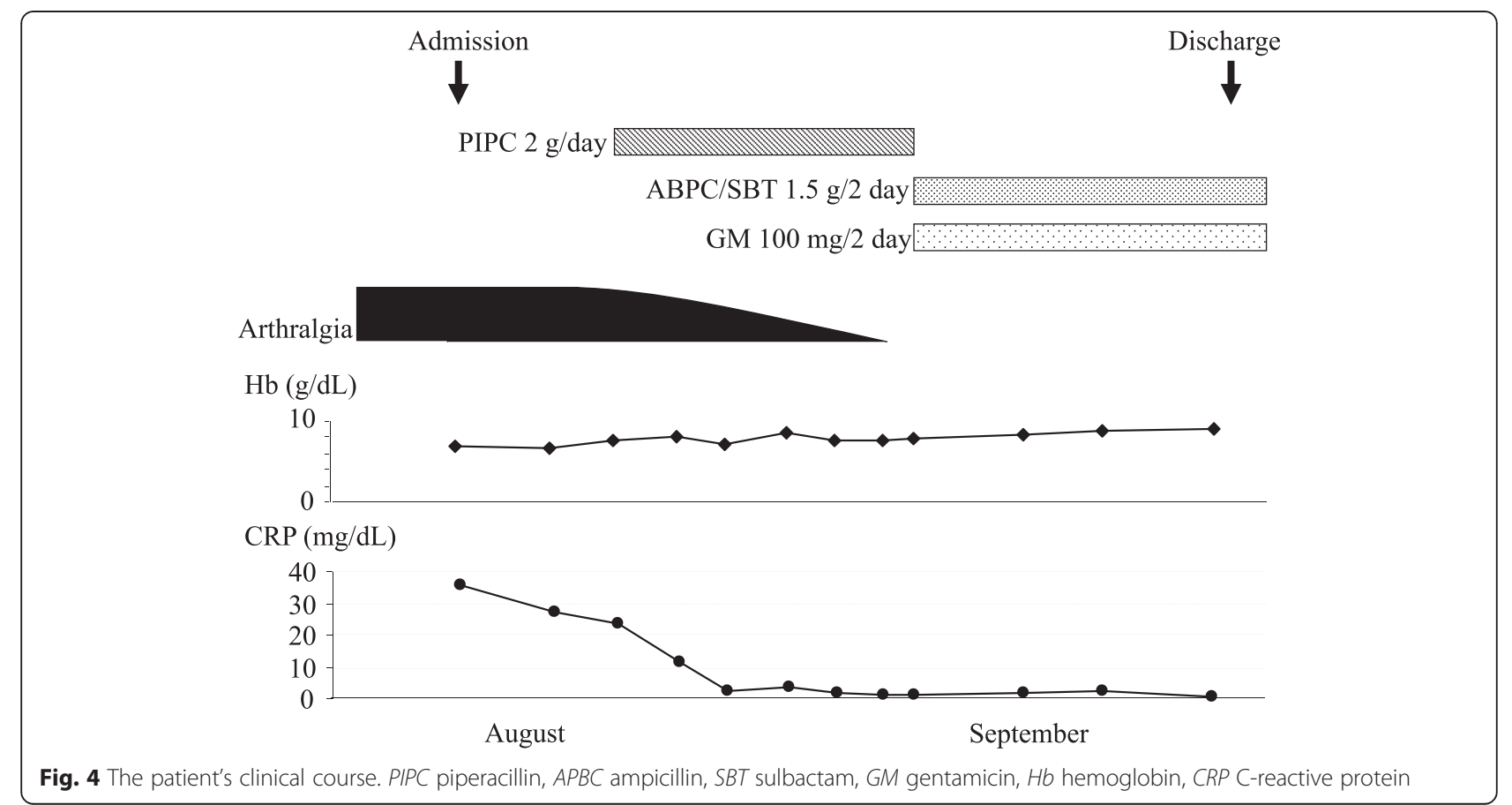


bacteria. However, reports of infectious diseases that were caused by this species are gradually being published. The clinical characteristics of the 28 reported cases of $K$. kristinae infections are summarized in Tables 2 and 3 [4-16]. Most K. kristinae infections are reported as infections in immunocompromised hosts or patients with underlying malignancy, ESRD requiring dialysis, diabetes mellitus, and prematurity. Although published reports of K. kristinae infections are rare, the prevalence of this infection, especially among immunocompromised hosts, may be underestimated, as most physicians likely do not consider this organism as a pathogen.

Patients who are receiving RRT often have infectious diseases, although the identification of their causative microorganism(s) and focus of infection are difficult to accurately diagnose. Furthermore, patients who are receiving RRT are frequently immunocompromised and may have atypical infectious organisms that are considered normal bacterial flora in healthy individuals [17]. Among patients who are undergoing RRT, the host's immunity may be compromised by uremia that interferes with $\mathrm{T}$ cell and $\mathrm{B}$ cell function, macrophage phagocytosis, and antigen presentation, which can increase the risk of infection [17]. The population of patients with ESRD who receive RRT has been increasing worldwide, and this population included 314,180 Japanese patients in December 2013 [18]. Furthermore, the number of patients with diabetes mellitus is increasing, and diabetic nephropathy has recently become the leading cause $(43.8 \%)$ of RRT in Japan [18]. Because ESRD and diabetes mellitus can both lead to an immunocompromised status and increase susceptibility to unusual infections,

Table 2 Demographic data, treatments, and outcomes for 28 patients with Kocuria kristinae infections

\begin{tabular}{|c|c|c|c|c|c|c|}
\hline Case & Antibiotic regimen & Course (days) & TPN & Outcome & Ref. & Year \\
\hline 1 & Meropenem + glycopeptide $\rightarrow$ ciprofloxacin + clindamycin $\rightarrow$ catheter removal & NA & NA & Recovery & 4 & 2002 \\
\hline 2 & Levofloxacin & 14 & No & Recovery & 5 & 2005 \\
\hline 3 & Ceftriaxone + ofloxacin & 16 & NA & Death & 6 & 2008 \\
\hline 4 & $\begin{array}{l}\text { Azithromycin + ceftriaxone + vancomycin }+ \text { oseltamivir } \rightarrow \text { vancomycin }+ \text { clindamycin } \rightarrow \\
\text { oxacillin }\end{array}$ & 42 & Yes & Recovery & 7 & 2011 \\
\hline 5 & Vancomycin $\rightarrow$ teicoplanin $\rightarrow$ oxacillin & NA & Yes & Recovery & 8 & 2011 \\
\hline 6 & Piperacillin/tazobactam $\rightarrow$ ciprofloxacin & NA & Yes & Recovery & 8 & 2011 \\
\hline 7 & Oxacillin + vancomycin & NA & Yes & Recovery & 8 & 2011 \\
\hline 8 & Oxacillin & NA & Yes & Recovery & 8 & 2011 \\
\hline 9 & $\begin{array}{l}\text { Tobramycin } \rightarrow \text { cefotaxime }+ \text { tazobactam } \rightarrow \text { ciprofloxacin }+ \text { teicoplanin }+ \text { amoxicillin/ } \\
\text { clavulanic acid }\end{array}$ & 24 & No & Recovery & 9 & 2011 \\
\hline 10 & Cefazolin + cefepime & 14 & No & Recovery & 10 & 2011 \\
\hline 11 & Ceftriaxone + vancomycin & 14 & Yes & Recovery & 11 & 2012 \\
\hline 12 & Ceftriaxone + metronidazole $\rightarrow$ sulbactam/ampicillin + gentamicin & 25 & No & Death & 12 & 2013 \\
\hline 13 & No antibiotics & No & No & Unknown & 13 & 2013 \\
\hline 14 & Dicloxacillin + vancomycin + levofloxacin & 21 & No & Recovery & 14 & 2014 \\
\hline 15 & Ceftriaxone + amikacin + cefotaxime & 16 & No & Recovery & 14 & 2014 \\
\hline 16 & Vancomycin & 10 & NA & Recovery & 15 & 2014 \\
\hline 17 & Vancomycin & 7 & NA & Recovery & 15 & 2014 \\
\hline 18 & Levofloxacin & 7 & NA & Recovery & 15 & 2014 \\
\hline 19 & Linezolid & 14 & NA & Recovery & 15 & 2014 \\
\hline 20 & Vancomycin & 5 & NA & Recovery & 15 & 2014 \\
\hline 21 & Vancomycin + ceftazidime & 10 & Yes & Recovery & 16 & 2015 \\
\hline 22 & Vancomycin & 10 & Yes & Recovery & 16 & 2015 \\
\hline 23 & Vancomycin + ceftazidime & 10 & Yes & Recovery & 16 & 2015 \\
\hline 24 & Oxacillin + vancomycin & 9 & Yes & Recovery & 16 & 2015 \\
\hline 25 & Vancomycin + cefotaxime & 12 & Yes & Recovery & 16 & 2015 \\
\hline 26 & Vancomycin + cefotaxime & 10 & Yes & Recovery & 16 & 2015 \\
\hline 27 & Vancomycin + piperacillin/tazobactam & 10 & No & Recovery & 16 & 2015 \\
\hline 28 & Piperacillin $\rightarrow$ ampicillin/sulbactam + gentamicin & 30 & No & Recovery & Current & 2015 \\
\hline
\end{tabular}


Table 3 Clinical, demographic, and bacterial data from 28 patients with Kocuria kristinae infections

\begin{tabular}{|c|c|c|c|c|c|c|c|}
\hline Case & $\begin{array}{l}\text { Age, year } \\
\text { (month) }\end{array}$ & Sex & Country & Underlying disease & Isolation site & Catheters & Clinical presentation \\
\hline 1 & 51 & $\mathrm{~F}$ & Italy & Ovarian cancer, chemotherapy & $\begin{array}{l}\text { Blood, catheter } \\
\text { tip }\end{array}$ & CVC & Febrile neutropenia, sepsis \\
\hline 2 & 56 & M & $\begin{array}{l}\text { Hong } \\
\text { Kong }\end{array}$ & Gallstones & Biliary fluid & No & Acute cholecystitis \\
\hline 3 & 68 & M & France & $\begin{array}{l}\text { MDS, acute myelogenous leukemia, tuberculosis, } \\
\text { chemotherapy }\end{array}$ & Blood & CVC & Sepsis \\
\hline 4 & 29 & $\mathrm{~F}$ & USA & Pregnancy, hyperemesis gravidarum & Blood & CVC & Suppurative thrombosis \\
\hline 5 & 89 & $\mathrm{~F}$ & Taiwan & $\begin{array}{l}\text { Post-resection ischemic bowel status, short bowel } \\
\text { syndrome }\end{array}$ & Blood & CVC & Endocarditis \\
\hline 6 & 37 & $\mathrm{~F}$ & Taiwan & Gastric cancer & Blood & CVC & Bacteremia \\
\hline 7 & 2 & M & Taiwan & $\begin{array}{l}\text { Congenital short bowel syndrome, } \\
\text { hypogammaglobulinemia }\end{array}$ & Blood & CVC & Bacteremia \\
\hline 8 & 68 & $\mathrm{~F}$ & Taiwan & Gastric cancer & Blood & CVC & Bacteremia \\
\hline 9 & 78 & M & Italy & ESRD on CAPD & Peritoneal fluid & PDC & Peritonitis \\
\hline 10 & 69 & M & China & ESRD on CAPD & Peritoneal fluid & PDC & Peritonitis \\
\hline 11 & $0(4.0)$ & $\mathrm{F}$ & Turkey & Prolonged diarrhea, severe failure to thrive & Blood & CVC & $\begin{array}{l}\text { Black hairy tongue, fever, } \\
\text { bacteremia }\end{array}$ \\
\hline 12 & 74 & M & Italy & Diabetes mellitus & Blood & No & Foot ulcer, endocarditis, sepsis \\
\hline 13 & 20 & M & India & Urethral stricture & Urine & UC & Malaise \\
\hline 14 & 20 & $\mathrm{~F}$ & Mexico & ESRD on $\mathrm{HD}$ & Blood & CVC & Bacteremia \\
\hline 15 & 68 & M & Mexico & ESRD on CAPD & Peritoneal fluid & PDC & Peritonitis \\
\hline 16 & 65 & M & India & Lung small cell carcinoma & Sputum & NA & Leukocytosis (neutrophillia) \\
\hline 17 & 65 & M & India & Carcinoma soft palate & Sputum & NA & Leukocytosis (neutrophillia) \\
\hline 18 & 41 & $\mathrm{~F}$ & India & Carcinoma lip and gingival sulcus & Sputum & NA & Leukocytosis (neutrophillia) \\
\hline 19 & 39 & M & India & Squamous cell carcinoma of the buccal mucosa & pus & NA & Leukocytosis (neutrophillia) \\
\hline 20 & 42 & $\mathrm{~F}$ & India & Ductal carcinoma of the breast & pus & NA & Leukocytosis (neutrophillia) \\
\hline 21 & $0(1.4)$ & M & Taiwan & Prematurity & Blood & CVC & Sepsis \\
\hline 22 & $0(0.6)$ & M & Taiwan & Prematurity & Blood & CVC & Sepsis \\
\hline 23 & $0(0.7)$ & $\mathrm{F}$ & Taiwan & Prematurity & Blood & CVC & Sepsis \\
\hline 24 & $0(1.1)$ & $\mathrm{F}$ & Taiwan & Prematurity & Blood & CVC & Sepsis \\
\hline 25 & $0(0.6)$ & $\mathrm{F}$ & Taiwan & Prematurity & $\begin{array}{l}\text { Blood, catheter } \\
\text { tip }\end{array}$ & CVC & Sepsis \\
\hline 26 & $0(0.6)$ & $\mathrm{F}$ & Taiwan & Prematurity & $\begin{array}{l}\text { Blood, catheter } \\
\text { tip }\end{array}$ & CVC & Sepsis \\
\hline 27 & $0(2.5)$ & $\mathrm{F}$ & Taiwan & Leukemia & $\begin{array}{l}\text { Blood, catheter } \\
\text { tip }\end{array}$ & CVC & Neutropenic fever \\
\hline 28 & 61 & M & Japan & ESRD on $\mathrm{HD}$, diabetes mellitus & Blood & No & Septic arthritis, endocarditis \\
\hline
\end{tabular}

Age is presented as year (month)

Abbreviations: ESRD end-stage renal disease, CAPD chronic ambulatory peritoneal dialysis, $H D$ hemodialysis, CVC central venous catheter, $P D C$ peritoneal dialysis catheter, UC urinary catheter

patients with ESRD and diabetes mellitus are likely very susceptible to uncommon and usually non-pathogenic microorganisms. However, Kocuria spp. infections are rarely reported among patients with diabetes and RRT. We speculate that there are two reasons for this phenomenon. First, most physicians believe that Kocuria spp., Micrococcus spp., and especially K. kristinae are non-pathogenic and might not consider these organisms as potentially causative organisms, despite observing positive culture results. Second, most Kocuria spp. and Micrococcus spp. are sensitive to almost all antibiotics (except ampicillin and erythromycin), and monotherapy often results in good outcomes [19]. In this context, Japanese investigators have reported that the causes of fever of unknown origin (FUO) are infection (27.7\%), non-infectious inflammatory disease (18.4\%), malignancy 
(10.2 \%), other conditions (14.8\%), and unknown causes (28.9 \%) [20]. Thus, given the frequency of an unknown cause of FUO, we usually use empirical antibiotics to treat infections of unknown origin until culture results are available. Therefore, it is possible that repeating cultures will not identify the same microorganisms in each culture, as the empirical antibiotics might cure the infection without severe clinical events (e.g., sepsis) before the second sample is collected. Interestingly, infection is the primary cause of death among Japanese patients who are receiving RRT (26.5 \%) [19], and it is likely that the number of patients with diabetes and RRT is going to continue increasing. Furthermore, the population of elderly Japanese patients is also increasing, which will likely result in a larger number of immunocompromised hosts. Based on these factors, it is possible that an increasing number of patients may have underlying $K$. kristinae infection that is not diagnosed until they develop severe complications, such as bacteremia and endocarditis. Therefore, it may be prudent to assess the pathogenic capacity of $K$. kristinae and any other unusual microorganisms, even if an infection of unknown origin improves after antibiotic monotherapy in patients who are elderly, have diabetes, or are receiving RRT. Moreover, clinicians should not underestimate the importance of a positive culture result for $K$. kristinae, as patients may experience repeated infections, develop severe infectious complications, and possibly die from this infection.

During recent years, many investigators have reviewed the diagnostic value of FDG-PET-CT. Although FDG was first developed to trace brain metabolism [21], FDG-PETCT has subsequently been recognized as an early diagnostic tool that has high sensitivity for malignancies, such as melanoma and cervical, lung, breast, gastrointestinal, ovarian, and prostatic cancers [22]. Furthermore, recent studies have found that FDG-PET-CT could detect the existence of inflammatory diseases and determine their severity and extent [23]. Although contrast-enhanced CT and/or MRI are performed for diagnosing and examining malignancies, infections, and autoimmune diseases, the use of contrast agents for these techniques is often contraindicated in patients with severe renal insufficiency, as these agents increase the incidence of their adverse effects. In contrast, FDG-PET-CT is considered safer and simpler for dialysis patients, compared to contrast-enhanced CT or MRI. Therefore, we suggest that FDG-PET-CT should be used for diagnosing and evaluating dialysis patients if the origin of their disease is unclear and that physicians should not delay this diagnostic imaging, which can lead to a poor prognosis.

\section{Conclusions}

We report the first case of $K$. kristinae septic arthritis associated with infectious endocarditis in a chronic hemodialysis patient with diabetes mellitus. We suggest that physicians should consider the pathogenic potential of K. kristinae, as it can cause fatal infections (e.g., septic arthritis and infectious endocarditis) in immunocompromised patients or patients with diabetes and RRT. We also suggest that FDG-PET-CT is a very useful and safe diagnostic tool, which can help identify the focus of inflammatory disorders in dialysis patients.

\section{Consent}

Written informed consent was obtained from the patient for publication of this case report and the accompanying images. A copy of the written consent is available for review by the Editor-in-Chief of this journal.

\section{Competing interests}

The authors declare that they have no competing interests.

\section{Authors' contributions}

$\mathrm{TH}, \mathrm{YS}, \mathrm{KO}$, and $\mathrm{KI}$ performed the laboratory testing. $\mathrm{TH}$ and $\mathrm{YT}$ drafted the manuscript. All authors read and approved the final manuscript.

Received: 28 November 2015 Accepted: 8 April 2016

Published online: 13 June 2016

\section{References}

1. Kloos WE, Tornabene TG, Schleifer KH. Isolation and characterization of micrococci from human skin, including two new species: Micrococcus lylae and Micrococcus kristinae. Int J Syst Evol Bacteriol. 1974:24:79-101.

2. Stackebrandt E, Koch C, Gvozdiak O, Schumann P. Taxonomic dissection of the genus Micrococcus: Kocuriagen. nov., Nesterenkoniagen. nov., Kytococcusgen. nov., Dermacoccus gen. nov., and Micrococcus Cohn 1872 gen. emend. Int J Syst Bacteriol. 1995:45:682-92.

3. Cordero MR, Zumalacárregui JM. Characterization of micrococcaceae isolated from salt used for Spanish dry-cured ham. Lett Appl Microbiol. 2000;31:303-6.

4. Basaglia G, Carretto E, Barbarini D, et al. Catheter-related bacteremia due to Kocuria kristinaein a patient with ovarian cancer. J Clin Microbiol. 2002;40:311-3.

5. Ma ES, Wong $\mathrm{CL}$, Lai KT, et al. Kocuria kristinae infection associated with acute cholecystitis. BMC Infec Dis. 2005;5:60.

6. Martinaud C, Gaillard T, Brisou P, Gisserot O, de Jaureguiberry JP. Bacteremia caused by Kocuria kristinae in a patient with acute leukemia. Med Mal Infect. 2008:38:165-6 [in French].

7. Dunn R, Bares S, David MZ. Central venous catheter-related bacteremia caused by Kocuria kristinae: case report and review of the literature. Ann Clin Microbiol Antimicrob. 2011;10:31.

8. Lai CC, Wang JY, Lin SH, et al. Catheter-related bacteraemia and infective endocarditis caused by Kocuriaspecies. Clin Microbiol Infect. 2011;17:190-2.

9. Calini A, Mattei R, Lucarotti I, Bartelloni A, Rosati A. Kocuria kristinae: an unusual cause of acute peritoneal dialysis-related infection. Perit Dial Int. 2011;31:105-7.

10. Cheung C, Cheng N, Chau C, Li CS. An unusual organism for CAPD related peritonitis: Kocuria kristinae. Perit Dial Int. 2011;31:107-8.

11. Karadag Oncel E, Boyraz MS, Kara A. Black tongue associated with Kocuria (Micrococcus) kristinae bacteremia in a 4-month-old infant. Eur J Pediatr. 2012;171:593.

12. Citro R, Prota C, Greco L, et al. Kocuria kristinae endocarditis related to diabetic foot infection. J Med Microbiol. 2013;62:932-4

13. Tewari R, Dudeja M, Das AK, Nandy S. Kocuria kristinae in catheter associated urinary tract infection: a case report. J Clin Diagn Res. 2013;7:1692-3.

14. Chávez Valencia V, Orizaga de la Cruz C, Aguilar Bixano O, Huerta Ruíz MK, Sánchez Estrada EE. Infections due to Kocuria kristinae: case reports of two patients and review of the literature. Gac Med Mex. 2014;150 Suppl 2:183-5 [in Spanish] 
15. Ahmed NH, Biswal I, Roy P, Grover RK. Kocuria kristinae, an unusual pathogen causing opportunistic infections in patients with malignancy. Indian J Med Microbiol. 2014;32:456-8.

16. Chen HM, Chi H, Chiu NC, Huang FY. Kocuria kristinae: a true pathogen in pediatric patients. J Microbiol Immunol Infect. 2015;48:80-4.

17. Leone S, Suter F. Severe bacterial infections in haemodialysis patients. Infez Med. 2010;18:79-85.

18. Masakane I, Nakai S, Ogata S, et al. An overview of regular dialysis treatment in Japan (as of 31 December 2013). Ther Apher Dial. 2015;19:540-74.

19. Szczerba I. Susceptibility to antibiotics of bacteria from genera Micrococcus, Kocuria, Nesternkonia, Kytococcus and Dermacoccus. Med Dosw Mikrobiol. 2003;55:75-80 [in Polish]

20. Yamanouchi M, Uehara Y, Yokokawa H, et al. Analysis of 256 cases of classic fever of unknown origin. Intern Med. 2014;53:2471-5.

21. Reivich $M$, Kuhl D, Wolf $A$, et al. The [18F] fluorodeoxyglucose method for the measurement of local cerebral glucose utilization in man. Circ Res. 1979:44:127-37.

22. Gallamini A, Zwarthoed C, Borra A. Positron emission tomography (PET) in oncology. Cancers (Basel). 2014;6:1821-89.

23. Balink $H$, Verberne $H J$, Bennink RJ, van Eck-Smit BL. A rationale for the use of F18-FDG PET/CT in fever and inflammation of unknown origin. Int J Mol Imaging. 2012. doi: 10.1155/2012/165080.

Submit your next manuscript to BioMed Central and we will help you at every step:

- We accept pre-submission inquiries

- Our selector tool helps you to find the most relevant journal

- We provide round the clock customer support

- Convenient online submission

- Thorough peer review

- Inclusion in PubMed and all major indexing services

- Maximum visibility for your research

Submit your manuscript at www.biomedcentral.com/submit
) Biomed Central 